\title{
A tale of two eagles
}

DOI: https://doi.org/10.32870/ eees.v26i76.7115
Marcos Pablo Moloeznik
El autor del libro aquí reseñado, Craig Deare, profesor de la National Defense University y teniente coronel retirado del Ejército de Estados Unidos, persigue un propósito directo al escribirlo: mejorar la relación bilateral de defensa entre México y su vecino del norte.

Dicha finalidad obedece a una dimensión personal que subyace a esta obra: Craig Deare vivió varios años en Guadalajara, México, y de hecho es egresado del Instituto de Ciencias, en dicha ciudad. De esa época conserva a sus mejores amigos. Más tarde, se trasladó a Arizona, donde obtuvo una titulación universitaria y sirvió a lo largo de veinte años en el Ejército estadounidense, la mayor parte como oficial del foreign area especializado en América Latina, y en especial en México. En este último país, se desempeñó como attaché de defensa para, posteriormente, ejercer como director sobre México en la oficina del secretario de Defensa de Estados Unidos.

Deare obtuvo maestría y doctorado en la Escuela de Estudios Internacionales Avanzados de la prestigiosa Universidad Johns Hopkins con una disertación sobre La relación de defensa bilateral entre Estados
Craig A. Deare (2017). A Tale of Two Eagles. The US-Mexico Bilateral Defense Relationship Post-Cold War. Lanham: Rowman \& Littlefield. 
Unidos y México durante la presidencia de Carlos Salinas de Gortari. Desde enero de 2001, Deare se desempeña como profesor en la Universidad de la Defensa Nacional (National Defense University), en Washington, D. C.

En cuanto al libro que nos ocupa, este está integrado por ocho bloques desarrollados a lo largo de cuatrocientas tres páginas, que incluyen el necesario marco histórico y lo que el autor identifica como las sucesivas etapas de las relaciones militares bilaterales de la post Guerra Fría, es decir, desde fines de la década de los años ochenta del siglo xx. En otras palabras, da cuenta de aproximadamente tres décadas del devenir histórico de las relaciones México-Estados Unidos a través del tratamiento inédito de la dimensión militar.

De esta manera, se someten a análisis dichas relaciones a la luz de cada sexenio de las presidencias mexicanas, en sucesivos capítulos: Carlos Salinas de Gortari, Ernesto Zedillo Ponce de León, Vicente Fox Quesada y Felipe Calderón Hinojosa, y se incluye un estudio preliminar del encabezado por Enrique Peña Nieto, esto último a manera de epílogo.

Se trata de un esfuerzo encomiable y sólido, soportado tanto en fuentes primarias como en las vivencias directas del autor, en especial si se tienen en cuentan las cerca de cincuenta entrevistas a profundidad llevadas a cabo a oficiales de las Fuerzas Armadas y a actores clave tanto de los Estados Unidos como de México, entre ellos el expresidente Vicente Fox, la mayoría de los embajadores mexicanos en Estados Unidos, los secretarios de Defensa y jefes del Estado Mayor Conjunto de la Unión Americana, los embajadores de Estados Unidos en México y otros funcionarios de primer nivel del Departamento de Defensa de la Unión Americana.

La ausencia de conocimientos sobre el otro (en especial de los gringos hacia México), el peso de la historia (intervencionismo de Estados Unidos y pérdida territorial mexicana), los intereses nacionales de cada país y su concepción sobre la soberanía, así como la desconfianza mutua (en particu- 
lar hacia los Estados Unidos) son los constantes a la vez que principales obstáculos de las relaciones bilaterales en el ámbito castrense que identifica el autor. Tratándose de México, es en el Ejército en el que descansa el mayor grado de desconfianza.

Por otro lado, y más allá de estos condicionantes, Craig Deare deja bien en claro que cada nueva Administración dificulta el desarrollo armónico de dichas relaciones; es decir, se trata del liderazgo político en ambos lados de la frontera, agravado por las burocracias de cada Estado-nación y por las diferencias en la dinámica y estilo de gestión en las mismas.

Ahora bien, en el capítulo tercero se analiza cómo la década de los ochenta, de la mano de la emergencia del concepto seguridad nacional y del narcotráfico en México, identificado desde entonces como su principal amenaza, constituye para el autor un punto de inflexión en las relaciones bilaterales de corte castrense, pues deja expedita una cooperación más estrecha a través de medios como la misión estadounidense de erradicación de las drogas en México. A decir de Deare, la visión del entonces jefe de personal del Ejército de los Estados Unidos, general Gordon Sullivan, al reconocer en México a un vecino y aliado importante, sentó las bases para una nueva era basada en el entendimiento y la cooperación en las relaciones bilaterales militares. Ex ante, fue durante el estallido de la Segunda Guerra Mundial cuando dichas relaciones alcanzaron su máximo apogeo, tal como lo ha explicado el general Francisco L. Urquizo en su obra 3 de Diana.

El mejoramiento de las relaciones bilaterales en el plano castrense respondió -siguiendo al autor aquí reseñadotanto a la llegada de Bill Clinton a la Presidencia de los Estados Unidos como al impacto del levantamiento zapatista en Chiapas, en 1994, que trajo aparejada la decisión del

Reseñas No.76 
Ejército mexicano de mejorar su equipo, que sería comprado en gran parte en Estados Unidos.

William J. Perry, a la sazón secretario de Defensa de Estados Unidos, fue otra figura clave para mejorar la relación bilateral, pues se convirtió en el primer secretario de Defensa en visitar México (1995) y establecer un Grupo de Trabajo Bilateral (BWG, por sus siglas en inglés). Cabe recordar que Perry fue quien, en Williamsburg, Virginia, convocó y puso en marcha el mecanismo denominado Conferencia de Ministros de Defensa de las Américas. La XIII Conferencia de Ministros de Defensa de las Américas tuvo a México como sede y se realizó del 7 al 10 de octubre de $2018 .{ }^{1}$

Por otra parte, entre los obstáculos en el ámbito de la cooperación bilateral militar, el autor pone de relieve, entre otros, tres casos: 1) los poco más de setenta helicópteros UH-1 Huey entregados por Estados Unidos y devueltos por nuestro país al no ser aptos por el techo (altitud) que presenta México (orografía, accidentes geográficos y, sobre todo, altas montañas, es decir, determinismo geográfico); 2) el mensaje en que el entonces director de la Oficina de Control y Prevención de Drogas de Estados Unidos, el general Barry McCaffrey, llamó a su homólogo mexicano, el general José de Jesús Gutiérrez Rebollo, el llamado zar antidrogas de México, un hombre de integridad, poco antes de que las autoridades mexicanas arrestaran a Rebollo por sus nexos con organizaciones del narcotráfico; y 3) la operación Casa Blanca del Gobierno de los Estados Unidos, que no fue notificada al Gobierno mexicano antes de hacerse pública.

Con la llegada del primer Gobierno de alternancia en México, en el 2000, la relación bilateral comenzó mal: el entonces presidente mexicano Vicente Fox denunció al Tra-

I. Se trata de un foro regional en el que participan los ministros y secretarios de Defensa del hemisferio con el objetivo de promover el conocimiento recíproco, medidas de confianza mutuas e intercambiar experiencias, ideas, propuestas y buenas prácticas en el ámbito de dicha política sectorial. 
tado de Río (TIAR) apenas cuatro días antes de los atentados terroristas del 11 de septiembre de 2001 en Estados Unidos. A raíz de esto, el TIAR fue invocado por Brasil y demostró su vigencia. Por otro lado, el libro también retoma la creación del Comando del Norte (NORTHCOM), que en su momento fue considerado por México como un menoscabo de su soberanía.

A pesar de todo esto, el balance general de las relaciones bilaterales militares durante el sexenio foxista fue positivo, y las mismas se fortalecieron a lo largo de la Administración de Felipe Calderón, en el marco de la denominada guerra contra el narcotráfico, que contó con la activa cooperación de su vecino del norte.

Recapitulando, más allá del título de la obra, que hace referencia más bien al fin de la Guerra Fría, lo cierto es que los efectos de esta respecto a las relaciones bilaterales no se hicieron sentir tanto como el de los Gobiernos de alternancia encabezados por Fox y Calderón en el marco de la amenaza global del terrorismo y la propia del narcotráfico, que en materia de cooperación bilateral castrense verificó su continuidad durante el sexenio de Enrique Peña Nieto (2012-2018).

El libro señalado contribuye significativamente a entender las relaciones entre México y Estados Unidos de las últimas tres décadas a partir de la dimensión militar de la diplomacia y, por ende, se erige en una fuente de consulta indispensable para los estudiosos de las relaciones internacionales y de obligada lectura para los diplomáticos de ambos vecinos.

Reseñas No.76 